NASA/TM-1999-209175

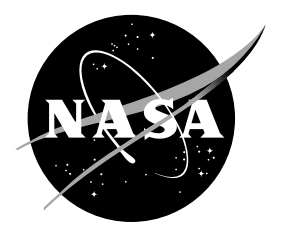

\title{
Compatibility Conditions of Structural Mechanics
}

Surya N. Patnaik

Ohio Aerospace Institute, Cleveland, Ohio

Rula M. Coroneos and Dale A. Hopkins

Glenn Research Center, Cleveland, Ohio 
Since its founding, NASA has been dedicated to the advancement of aeronautics and space science. The NASA Scientific and Technical Information (STI) Program Office plays a key part in helping NASA maintain this important role.

The NASA STI Program Office is operated by Langley Research Center, the Lead Center for NASA's scientific and technical information. The NASA STI Program Office provides access to the NASA STI Database, the largest collection of aeronautical and space science STI in the world. The Program Office is also NASA's institutional mechanism for disseminating the results of its research and development activities. These results are published by NASA in the NASA STI Report Series, which includes the following report types:

- TECHNICAL PUBLICATION. Reports of completed research or a major significant phase of research that present the results of NASA programs and include extensive data or theoretical analysis. Includes compilations of significant scientific and technical data and information deemed to be of continuing reference value. NASA's counterpart of peerreviewed formal professional papers but has less stringent limitations on manuscript length and extent of graphic presentations.

- TECHNICAL MEMORANDUM. Scientific and technical findings that are preliminary or of specialized interest, e.g., quick release reports, working papers, and bibliographies that contain minimal annotation. Does not contain extensive analysis.

- CONTRACTOR REPORT. Scientific and technical findings by NASA-sponsored contractors and grantees.
- CONFERENCE PUBLICATION. Collected papers from scientific and technical conferences, symposia, seminars, or other meetings sponsored or cosponsored by NASA.

- SPECIAL PUBLICATION. Scientific, technical, or historical information from NASA programs, projects, and missions, often concerned with subjects having substantial public interest.

- TECHNICAL TRANSLATION. Englishlanguage translations of foreign scientific and technical material pertinent to NASA's mission.

Specialized services that complement the STI Program Office's diverse offerings include creating custom thesauri, building customized data bases, organizing and publishing research results ... even providing videos.

For more information about the NASA STI Program Office, see the following:

- Access the NASA STI Program Home Page at http://www.sti.nasa.gov

- E-mail your question via the Internet to help@sti.nasa.gov

- Fax your question to the NASA Access Help Desk at (301) 621-0134

- Telephone the NASA Access Help Desk at (301) 621-0390

- Write to:

NASA Access Help Desk

NASA Center for AeroSpace Information 7121 Standard Drive

Hanover, MD 21076 
NASA/TM-1999-209175

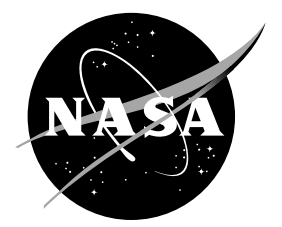

\section{Compatibility Conditions of Structural Mechanics}

Surya N. Patnaik

Ohio Aerospace Institute, Cleveland, Ohio

Rula M. Coroneos and Dale A. Hopkins

Glenn Research Center, Cleveland, Ohio

National Aeronautics and

Space Administration

Glenn Research Center 


\section{Acknowledgment}

The authors have benefited from discussion with Dr. Michael J. Zehe of NASA Glenn Research Center and express their gratitude to him.

Available from

NASA Center for Aerospace Information 7121 Standard Drive

Hanover, MD 21076

Price Code: A03
National Technical Information Service 5285 Port Royal Road Springfield, VA 22100 Price Code: A03 


\title{
Compatibility Conditions of Structural Mechanics
}

\author{
SURYA N. PATNAIK \\ Ohio Aerospace Institute \\ 22800 Cedar Point Rd. \\ Brook Park, Ohio 44142 \\ RULA M. CORONEOS AND DALE A. HOPKINS \\ National Aeronautics and Space Administration \\ Glenn Research Center \\ Cleveland, Ohio 44135
}

\section{SYMBOLS}

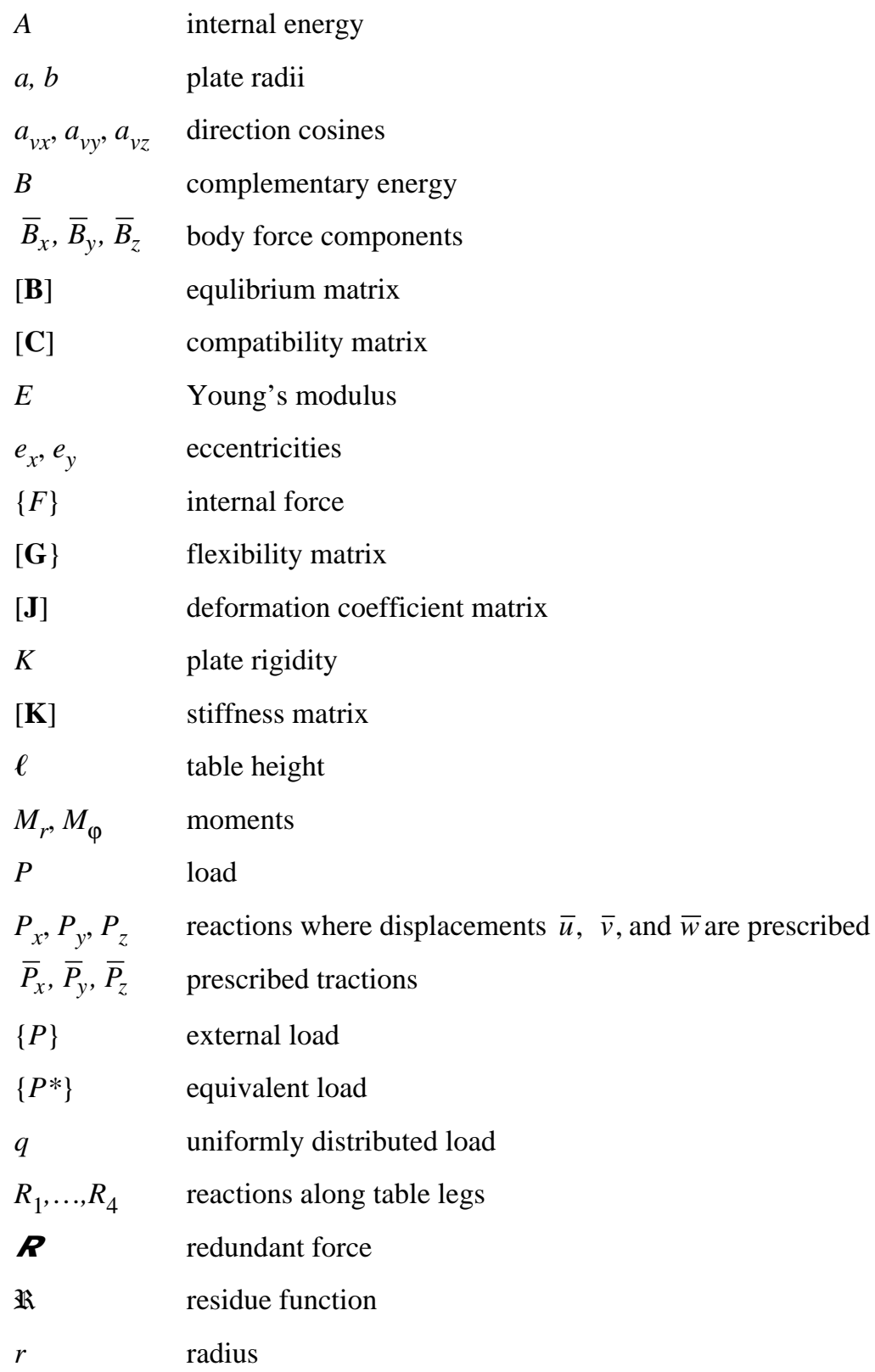


$\Delta t \quad$ temperature differential

$u, v, w \quad$ displacement components

V volume

W potential of work done

$x, y, z \quad$ Cartesian coordinates

$\beta \quad$ deformation

$\beta^{0} \quad$ initial deformation

$\gamma_{x y}, \gamma_{y z}, \gamma_{z x} \quad$ shear strain components

$\varepsilon_{x}, \varepsilon_{y}, \varepsilon_{z} \quad$ normal strain components

$\theta_{x}, \theta_{y} \quad$ rotations

$v \quad$ Poisson's ratio

$\pi_{s} \quad$ variational functional

$\sigma_{x}, \sigma_{y}, \sigma_{z} \quad$ normal stress components

$\tau_{x y}, \tau_{y z}, \tau_{z x} \quad$ shear stress components

$\varphi_{1}, \varphi_{2}, \varphi_{3} \quad$ stress functions

BCC boundary compatibility conditions

BMF Beltrami-Michell formulation

CBMF completed Beltrami-Michell formulation

CC compatibility conditions

DDR deformation displacement relations

$\mathrm{EE} \quad$ equilibrium equations

IFM integrated force method

IFMD dual integrated force method

\section{SUMMARY}

The theory of elasticity has camouflaged a deficiency in the compatibility formulation since 1860 . In structures the ad hoc compatibility conditions through virtual "cuts" and closing "gaps" are not parallel to the strain formulation in elasticity. This deficiency in the compatibility conditions has prevented the development of a direct stress determination method in structures and in elasticity. We have addressed this deficiency and attempted to unify the theory of compatibility. This work has led to the development of the integrated force method for structures and the completed Beltrami-Michell formulation for elasticity. The improved accuracy observed in the solution of numerical examples by the integrated force method can be attributed to the compliance of the compatibility conditions. Using the compatibility conditions allows mapping of variables and facile movement among different structural analysis formulations. This paper reviews and illustrates the requirement of compatibility in structures and in elasticity. It also describes the generation of the conditions and quantifies the benefits of their use. The traditional analysis methods and available solutions (which have been obtained bypassing the missed conditions) should be verified for compliance of the compatibility conditions. 


\section{INTRODUCTION}

The equilibrium equations and the compatibility conditions required for the analysis of stress in an elastic continuum were formulated by Cauchy and Saint-Venant during the first and third quarters of the nineteenth century, respectively. Cauchy's stress formulation was complete, with field equations and boundary conditions. Saint-Venant formulated the field equations in 1860 but did not provide the compatibility conditions on the boundary. Traditional compatibility theory in structures has been developed through the concept of redundant forces, with virtual "cuts" and subsequent closing of the "gaps." In elasticity the field equations generated through Saint-Venant's strain formulation are not parallel to the concept of cuts and closed gaps in structures. The compatibility formulation differed in elasticity and in structures. In other words, compatibility theory has concealed a weak spot since the strain formulation in 1860. The deficiency has prevented the development of a direct structural analysis method, even though the origin of the science can be traced back to the cantilever experiment of Galileo, conducted four centuries ago (ref. 1)

If compatibility is not required (as in the analysis of determinate structures), the method of forces represents the most efficient formulation. This method heretofore could not be extended to the analysis of indeterminate structures because of the weakness in compatibility theory. The compatibility barrier blocked the natural growth of the method, causing it to split into the stiffness method and the redundant force method as depicted in Fig. 1. The stiffness method has made magnificent progress, but the ad hoc redundant force formulation has disappeared for all practical purposes because of its limited scope (refs. 2 and 3 ).

Our research has attempted to extend the method of forces to the analysis of indeterminate structures. The basic concept of the method is expressed in the following symbolic equation (devised through discussions with Richard $\mathrm{H}$. Gallagher):

$$
\left[\frac{\text { Equilibrium equation }}{\text { Compatibility condition }}\right]\{\text { Stress }\}=\left[\frac{\text { Mechanical load }}{\text { Initial deformation }}\right]
$$

For stress analysis the equilibrium equation (EE) represents the necessary condition. Sufficiency is achieved through the compatibility conditions (CC). Even though a method corresponding to equation (1) could not be developed, such a formulation was envisioned by Michell and is described by Love (ref. 4) in the following quotation:

It is possible by taking account of these relations [compatibility conditions] to obtain a complete system of equations [eq. (1)] which must be satisfied by stress components, and thus the way is open for a direct determination of stress without the intermediate steps of forming and solving differential equations to determine the components of displacements.

At the turn of the twentieth century Beltrami and Michell attempted to formulate a direct method in elasticity with stress $\{\sigma\}$ as the unknown, referred to as the Beltrami-Michell formulation (BMF). Its field equation $(\mathrm{L}\{\sigma\}=$ $\{P\})$, was obtained by coupling the EE and the CC. The BMF had limited scope because the compatibility conditions on the boundary were not treated. For discrete structural analysis a method that can be considered parallel to the BMF with internal force $\{F\}$ as the unknown and the governing equation $([\mathbf{S}]\{F\})=\{P\}$ was not available during the formative 1960's.

We have addressed and attempted to unify compatibility theory in elasticity and in structures. In elasticity the compatibility conditions on the boundary have been identified (refs. 5 and 6). In structures our compatibility conditions are analogous to the strain formulation (ref. 7). Coupling the compatibility conditions to the equilibrium equations has led to the formulation of the integrated force method (IFM, ref. 8) for finite element structural analysis and the completed Beltrami-Michell formulation (CBMF) in elasticity (ref. 6). Both IFM and CBMF are versatile formulations applicable to static and dynamic analysis of linear and nonlinear structures. These methods and other analysis formulations are summarized in Table I. The IFM equations can be specialized to obtain the stiffness method (refs. 9 and 10) and the classical force method (ref. 11). Through the IFM matrices the hybrid and total formulations can be defined. The variational functional of the integrated force method can be specialized to obtain the functionals of the other methods given in Table I. The IFM equations allow free movement from stress to displacement and vice versa.

This paper is an invited paper in the International Journal of Numerical Methods in Engineering commemorating Richard H. Gallagher (1927-1997), who was a co-contributor to the theory of the integrated force method (refs. 7, 8, and 12). The paper reviews and illustrates the requirement of compatibility in structures and in elasticity. 
It discusses the role of compatibility in structures by considering Navier's table problem as an example. It also illustrates the necessity of the boundary compatibility conditions in elasticity through the analysis of a composite plate. We generated the three-dimensional compatibility conditions on the boundary from the stationary conditions of the IFM variational functional. We also quantified the benefits from their use in structural analysis by solving three examples. The paper is completed with discussions and conclusions.

\section{REQUIREMENT OF COMPATIBILITY CONDITIONS}

A direct determination of the six stress components requires six equations - three equilibrium equations and three compatibility conditions. However, indirect methods can be obtained by transforming stress into displacement or scalar function. The indirect methods emphasize either equilibrium equations or compatibility conditions. However, confirming the accuracy of the response generated by the direct or indirect methods requires satisfying the EE and the CC. Likewise, analysis of indeterminate structures requires both equilibrium and compatibility. The requirement of compatibility is illustrated by considering both Navier's table problem for structures and a composite circular plate in elasticity.

\section{Navier's Table Problem}

Navier attempted to determine the four reactions $\left(R_{1}, R_{2}, R_{3}\right.$, and $\left.R_{4}\right)$ along the legs of the table shown in Fig. 2. The symmetrical table is made of wood, rests on a level stone floor, and is subjected to a load $P$ with eccentricities $e_{x}$ and $e_{y}$. The table height is $\ell$, and the distances between the legs along the $x$ and $y$ directions are $2 a$ and $2 b$, respectively. Young's modulus of the table leg material is $E$, and its cross-sectional area is $A$. The table top is considered rigid.

The IFM solution for the four reactions is obtained by augmenting Navier's three equilibrium equations with one compatibility condition:

$$
\left[\begin{array}{rrrr}
-1 & -1 & -1 & -1 \\
a & a & -a & -a \\
-b & b & b & -b \\
-1 & -1 & 1 & -1
\end{array}\right]\left\{\begin{array}{l}
R_{1} \\
R_{2} \\
R_{3} \\
R_{4}
\end{array}\right\}\left\{\begin{array}{r}
-P \\
-e_{y} P \\
e_{x} P \\
---\frac{0}{0}
\end{array}\right\}
$$

Solving the IFM equation yields the four reactions as follows:

$$
\left\{\begin{array}{l}
R_{1} \\
R_{2} \\
R_{3} \\
R_{4}
\end{array}\right\}=\frac{P}{4}\left[\begin{array}{l}
1-r_{x}-r_{y} \\
1+r_{x}-r_{y} \\
1+r_{x}+r_{y} \\
1-r_{x}+r_{y}
\end{array}\right]=\frac{P}{4}\left\{\begin{array}{l}
1 \\
1 \\
1 \\
1
\end{array}\right\}_{r_{x}=r_{y}=0}
$$

where $r_{x}=e_{x} / a$ and $r_{y}=\mathrm{e}_{\mathrm{y}} / b$. Each leg carries one-quarter of the load when it has no eccentricity $\left(r_{x}=r_{y}=0.0\right)$.

Three displacement components are backcalculated as

$$
\left\{\begin{array}{c}
w \\
\theta_{x} \\
\theta_{y}
\end{array}\right\}=\left(\frac{\ell}{4 A E}\right)\left[\begin{array}{rrrr}
-1 & -1 & -1 & -1 \\
\frac{1}{a} & \frac{1}{a} & -\frac{1}{a} & -\frac{1}{a} \\
-\frac{1}{b} & \frac{1}{b} & \frac{1}{b} & -\frac{1}{b}
\end{array}\right]\left\{\begin{array}{l}
R_{1} \\
R_{2} \\
R_{3} \\
R_{4}
\end{array}\right\}
$$


If the table had three legs, its three reactions could have been calculated from the three equilibrium equations. Its fourth leg requires an additional compatibility condition. The IFM through its compatibility formulation provides the fourth equation in the matrix (see eq. (2)).

Instead of developing the compatibility condition Navier rewrote the three equilibrium equations in terms of the displacements $\left(w, \theta_{x}\right.$, and $\left.\theta_{y}\right)$ to obtain the three stiffness equations. Solution yielded the three displacements, from which the four reactions could be backcalculated. Generalization of this procedure, which is credited to Navier, became the popular stiffness method (refs. 13 and 14).

In the redundant force method one leg of the table was "cut" to obtain a three-legged determinate table. This determinate problem was solved for reactions and displacement $\Delta^{P}$ at the cut. The solution process was repeated for a load $R$, called a redundant force, in place of the reaction for the leg that had been cut. The resulting displacement $\Delta^{\mathrm{R}}$ at the cut was obtained. Because the physical table had no real cut, the gap was closed $\left(\Delta^{P}+\Delta^{\mathrm{R}}=0\right)$, yielding the value of the redundant reaction. Solving the determinate structure subjected to both the redundant reaction and the external load provided the result for the indeterminate problem. The generalization of this procedure became the redundant force method (refs. 2, 3, and 15).

\section{Composite Circular Plate}

The compatibility requirement in elasticity is illustrated through the example of a composite circular plate as shown in Fig. 3. The structure is made of an aluminum inner plate (I) of radius $a=6$ in. and a steel outer sector (II) of radius $b=12$ in. The inner plate (I) is subjected to a uniformly distributed load of intensity $q=100 \mathrm{psi}$, whereas the outer plate (II) is uniformly heated with a temperature differential of $\Delta t=50^{\circ} \mathrm{F}$. The thicknesses of the inner and outer plates are $h^{I}=0.2$ in. and $h^{I I}=0.15$ in., Young's moduli are $E^{I}=10.6 \times 10^{6}$ and $E^{I I}=30.0 \times 10^{6}$ psi, Poisson's ratios are $v^{I}=0.33$ and $v^{I I}=0.3$, respectively, the coefficient of expansion of the outer plate is $\alpha_{t}$.

In the completed Beltrami-Michell formulation the moments $M_{r}$ and $M_{\varphi}$ are considered as the unknowns. The plate has one field equilibrium equation and one compatibility condition as follows:

$$
\begin{gathered}
\frac{d^{2}}{d r^{2}}\left(r M_{r}\right)-\frac{d M_{\varphi}}{d r}+r q=0 \\
r \frac{d}{d r}\left(M_{\varphi}-v M_{r}\right)+(1+v)\left(M_{\varphi}-M_{r}\right)+K r \frac{\alpha_{t}}{h}\left(\frac{d \Delta t}{d r}\right)=0
\end{gathered}
$$

where the plate rigidity is defined as $K=E h^{3} /\left[12\left(1-v^{2}\right)\right]$. Solving the composite problem requires solving the two field equations for the six boundary conditions. One boundary compatibility condition occurs at the clamped boundary $(r=b)$ :

$$
\left[\frac{1}{K}\left(M_{\varphi}-v M_{r}\right)+\alpha_{t}\left(\frac{\Delta t}{h}\right)\right]^{I I}=0
$$

Three boundary conditions occur at the interface $(r=a)$ :

$$
\begin{gathered}
M_{r}^{I}=M_{r}^{I I} \\
{\left[\frac{d}{d r}\left(r M_{r}\right)-M_{\varphi}\right]^{I}=\left[\frac{d}{d r}\left(r M_{r}\right)-M_{\varphi}\right]^{I I}} \\
{\left[\frac{1}{K}\left(M_{\varphi}-v M_{r}\right)+\alpha_{t} \frac{\Delta t}{h}\right]^{I}=\left[\frac{1}{K}\left(M_{\varphi}-v M_{r}\right)+\alpha_{t} \frac{\Delta t}{h}\right]^{I I}}
\end{gathered}
$$


where the superscripts I and II refer to the two plate sectors at the interface. At the origin $(r=0)$

$$
\text { Moments are finite: }\left(M_{\varphi}^{I}, M_{r}^{I}\right)
$$

Solving the field equations yields moments for the inner plate as follows:

$$
\begin{aligned}
& M_{r}^{I}(r)=-\frac{B_{1}}{r^{2}}+\frac{1}{2} C_{1}\left(1+v^{I}\right) \log r+\frac{1}{4} C_{1}\left(1-v^{I}\right)+\frac{1}{2} D_{1}-\frac{1}{16}\left(3+v^{I}\right) q r^{2} \\
& M_{\varphi}^{I}(r)=-\frac{B_{1}}{r^{2}}+\frac{1}{2} C_{1}\left(1+v^{I}\right) \log r-\frac{1}{4} C_{1}\left(1-v^{I}\right)+\frac{1}{2} D_{1}-\frac{1}{16}\left(1+3 v^{I}\right) q r^{2}
\end{aligned}
$$

Likewise, solving for the outer plate with no distributed load gives

$$
\begin{aligned}
& M_{r}^{I I}(r)=-\frac{B_{2}}{r^{2}}+\frac{1}{2} C_{2}\left(1+v^{I I}\right) \log r+\frac{1}{4} C_{2}\left(1-v^{I I}\right)+\frac{1}{2} D_{2} \\
& M_{\varphi}^{I I}(r)=-\frac{B_{2}}{r^{2}}+\frac{1}{2} C_{2}\left(1+v^{I I}\right) \log r-\frac{1}{4} C_{2}\left(1-v^{I I}\right)+\frac{1}{2} D_{2}
\end{aligned}
$$

The six constants $\left(B_{1}, B_{2}, C_{1}, C_{2}, D_{1}\right.$, and $\left.D_{2}\right)$ are determined from the six boundary conditions. Substituting the numerical values for the parameters yields the following moment solutions:

For the inner plate $(0 \leq r \leq a)$

$$
\begin{aligned}
& M_{r}^{I}(r)=844.05-20.81 r^{2} \\
& M_{\varphi}^{I}(r)=844.05-12.44 r^{2}
\end{aligned}
$$

For the outer plate $(a \leq r \leq b)$

$$
\begin{aligned}
& M_{r}^{I I}(r)=2046.63-\left(5203.06 / r^{2}\right)-1170 \log r \\
& M_{\varphi}^{I I}(r)=2676.63+\left(5203.06 / r^{2}\right)-1170 \log r
\end{aligned}
$$

The displacement, if required, is obtained by integrating the deformation displacement relations. Calculating the integration for the constraints required using the kinematic boundary equations (refs. 16 and 17). The transverse displacements for the plate are as follows (ref. 16):

For the inner plate $(0 \leq r \leq a)$

$$
w^{I}(r)=3.1209-0.0356 r^{2}+0.1757 \times 10^{-3} r^{4}
$$

For the outer plate $(a \leq r \leq b)$

$$
w^{I I}(r)=5.3614-0.1344 r^{2}-0.7296 \log r+0.04417 r^{2} \log r
$$


The CBMF required the boundary compatibility conditions given by equations (7) and (8c). Because these conditions were not available, the CBMF could not be developed earlier. The CBMF can be transformed to obtain Navier's displacement method (ref. 18).

\section{GENERATION OF COMPATIBILITY CONDITIONS}

Strain, or deformation balance, represents the physical concept behind the compatibility conditions, which are controller type of relations. In elasticity the strains $\varepsilon$ are controlled, $f\left(\varepsilon_{x}, \varepsilon_{y}, \ldots, \gamma_{z x}\right)=0$; or in structures the deformations $\beta$ are balanced, $f\left(\beta_{1}, \beta_{2}, \ldots, \beta_{n}\right)=0$. The compatibility conditions are generated here first for elasticity and then for structures.

\section{Generation of Compatibility Conditions in Elasticity}

The field compatibility conditions can be derived by eliminating the displacements from the strain displacement relations (ref. 19). This technique has not yet been successfully extended to deriving the boundary compatibility conditions (BCC). At present the BCC have been generated from the stationary condition of the IFM variational functional. This functional $\pi_{s}$ has three terms: $A, B$, and $W$. For three-dimensional elasticity $\pi_{s}$ has the following explicit form:

$$
\pi_{s}=A+B-W
$$

Term $A$ represents the internal energy expressed in terms of stresses and displacements.

$$
A=\int_{\text {volume }}\left\{\sigma_{x} \frac{\partial u}{\partial x}+\sigma_{y} \frac{\partial v}{\partial y}+\sigma_{z} \frac{\partial w}{\partial z}+\tau_{x y}\left(\frac{\partial u}{\partial y}+\frac{\partial v}{\partial x}\right)+\tau_{y z}\left(\frac{\partial v}{\partial z}+\frac{\partial w}{\partial y}\right)+\tau_{z x}\left(\frac{\partial u}{\partial z}+\frac{\partial w}{\partial x}\right)\right\} d V
$$

Term $B$ represents the complementary energy. This term, expressed in terms of strain and stress function, has the following form:

$$
\begin{array}{r}
B=\int_{\text {volume }}\left\{\varepsilon_{x}\left(\frac{\partial^{2} \varphi_{3}}{\partial y^{2}}+\frac{\partial^{2} \varphi_{2}}{\partial z^{2}}\right)+\varepsilon_{y}\left(\frac{\partial^{2} \varphi_{1}}{\partial z^{2}}+\frac{\partial^{2} \varphi_{3}}{\partial x^{2}}\right)+\varepsilon_{z}\left(\frac{\partial^{2} \varphi_{2}}{\partial x^{2}}+\frac{\partial^{2} \varphi_{1}}{\partial y^{2}}\right)+\tau_{x y}\left(-\frac{\partial^{2} \varphi_{3}}{\partial x \partial y}\right)\right. \\
+\gamma_{x y}\left(-\frac{\partial^{2} \varphi_{1}}{\partial y \partial z}\right) \\
\left.+\gamma_{z x}\left(-\frac{\partial^{2} \varphi_{2}}{\partial z \partial x}\right)\right\} d V
\end{array}
$$

Term $W$ represents the potential of the work done due to the prescribed traction, displacement, and specified body force:

$$
W=\int_{\text {surface } \mathrm{S}_{1}}\left(\bar{P}_{x} u+\bar{P}_{y} v+\bar{P}_{z} w\right) d s+\int_{\text {surface } \mathrm{S}_{2}}\left(P_{x} \bar{u}+P_{y} \bar{v}+P_{z} \bar{w}\right) d s+\int_{\text {volume }}\left(\bar{B}_{x} u+\bar{B}_{y} v+\bar{B}_{z} w\right) d V
$$

where $\sigma_{x}, \sigma_{y}, \sigma_{z}, \tau_{x y}, \tau_{y z}$, and $\tau_{z x}$ are the six stress components; $\varepsilon_{x}, \varepsilon_{y}, \varepsilon_{z}, \gamma_{x y}, \gamma_{y z}$, and $\gamma_{z x}$ are the six strain components; $u, v$, and $w$ are the three displacement components; $\varphi_{1}, \varphi_{2}$, and $\varphi_{3}$ are the three stress functions; $\bar{P}_{x}, \bar{P}_{y}, \bar{P}_{z}$ are the three prescribed tractions; $P_{x}, P_{y}$, and $P_{z}$ are reactions where displacements $\bar{u}, \bar{v}$, and $\bar{w}$ are prescribed; and $\bar{B}_{x}, \bar{B}_{y}, \bar{B}_{z}$ are the three body force components. The stress functions are defined as 


$$
\begin{gathered}
\sigma_{x}=\frac{\partial^{2} \varphi_{3}}{\partial y^{2}+\frac{\partial^{2} \varphi_{2}}{\partial z^{2}} \quad \sigma_{y}=\frac{\partial^{2} \varphi_{1}}{\partial z^{2}}+\frac{\partial^{2} \varphi_{3}}{\partial x^{2}}} \quad \sigma_{z}=\frac{\partial^{2} \varphi_{2}}{\partial x^{2}}+\frac{\partial^{2} \varphi_{1}}{\partial y^{2}} \\
\tau_{x y}=-\frac{\partial^{2} \varphi_{3}}{\partial x \partial y} \quad \tau_{y z}=-\frac{\partial^{2} \varphi_{1}}{\partial y \partial z} \quad \tau_{x z}=-\frac{\partial^{2} \varphi_{2}}{\partial z \partial x}
\end{gathered}
$$

The selection of stress functions and their derivation from the field equations are given in reference 20 . The stationary condition of $\pi_{s}$ with respect to displacements $u, v$, and $w$ and stress functions $\varphi_{1}, \varphi_{2}$, and $\varphi_{3}$ yields all the equations of the completed Beltrami-Michell formulation. The set includes the known elasticity equations (three equilibrium equations and three compatibility conditions in the field; three boundary, equilibrium, or traction conditions; and three displacement continuity conditions on the boundary) available in standard textbooks (ref. 19). The stationary condition also yields the three additional boundary compatibility conditions. These conditions obtained in terms of strains, when expressed in terms of stresses for an isotropic material, are as follows:

$$
\begin{aligned}
& \frac{\partial}{\partial z}\left\{a_{v z}\left(\sigma_{y}-v \sigma_{z}-v \sigma_{x}\right)-a_{v y}(1+v) \tau_{y z}\right\}+\frac{\partial}{\partial y}\left\{a_{v y}\left(\sigma_{z}-v \sigma_{x}-v \sigma_{y}\right)-a_{v z}(1+v) \tau_{y z}\right\}=0 \\
& \frac{\partial}{\partial x}\left\{a_{v x}\left(\sigma_{z}-v \sigma_{x}-v \sigma_{y}\right)-a_{v z}(1+v) \tau_{z x}\right\}+\frac{\partial}{\partial z}\left\{a_{v z}\left(\sigma_{x}-v \sigma_{y}-v \sigma_{z}\right)-a_{v x}(1+v) \tau_{z x}\right\}=0 \\
& \frac{\partial}{\partial y}\left\{a_{v y}\left(\sigma_{x}-v \sigma_{y}-v \sigma_{z}\right)-a_{v x}(1+v) \tau_{x y}\right\}+\frac{\partial}{\partial x}\left\{a_{v x}\left(\sigma_{y}-v \sigma_{z}-v \sigma_{x}\right)-a_{v y}(1+v) \tau_{x y}\right\}=0
\end{aligned}
$$

where $a_{v x}, a_{v y}$, and $a_{v z}$ are the direction cosines of the outward normal vector to the boundary surface. The three BCC given by equation (16), missed since 1860, have been derived for the first time for a three-dimensional elastic continuum. These conditions, when added to the Beltrami-Michell formulation, complete the method of stress in elasticity. CBMF solutions for plates and cylindrical shells are reported in references 6 and 16.

\section{Compatibility Conditions for Finite Element Structural Analysis}

The compatibility conditions for finite element analysis are obtained as an extension of Saint-Venant's strain formulation in elasticity. The two steps of strain formulation are

1. Formulation of the strain displacement relations

2. Elimination of the displacements to obtain the compatibility conditions

For an illustration of the strain formulation consider the plane stress problem with its strain displacement relations:

$$
\varepsilon_{x}=\frac{\partial u}{\partial x} \quad \varepsilon_{y}=\frac{\partial v}{\partial y} \quad \gamma_{x y}=\frac{\partial u}{\partial y}+\frac{\partial v}{\partial x}
$$

The field $\mathrm{CC}$ are obtained by eliminating the displacements:

$$
\frac{\partial^{2} \varepsilon_{x}}{\partial y^{2}}+\frac{\partial^{2} \varepsilon_{y}}{\partial x^{2}}-\frac{\partial^{2} \gamma_{x y}}{\partial x \partial y}=0
$$

For discrete structures the deformation displacement relations (DDR) are equivalent to the strain displacement relations in elasticity. The DDR can be obtained by using the equality relation between internal strain energy and external work (ref. 7) as follows: 


$$
\{\beta\}=[\mathbf{B}]^{T}\{X\}
$$

where $[\mathbf{B}]$ is the $m \times n$ rectangular equilibrium matrix of the $\mathrm{EE},[\mathbf{B}]\{F\}=\{P\} ;\{\beta\}$ is the $n$-component deformation vector; and $\{X\}$ and $\{P\}$ are $m$-component displacement and load vectors, respectively. The DDR contain $r=n-m$ constraints on deformations, which represent the $r$ compatibility conditions. The $\mathrm{CC}$ are obtained by eliminating the $m$ displacements from the $n$ DDR as follows (ref. 8):

$$
[\mathbf{C}]\{\beta\}=\{0\}
$$

The deformation $\{\beta\}$ of structures is analogous to strain in elasticity. The rectangular and banded compatibility matrix [C] of dimension $r \times n$, has a full-row rank of $r$. It is independent of sizing design parameters (such as the area of the bars and the moments of inertia of the beams), material properties, and external loads (ref. 7).

\section{Compliance of Compatibility Conditions}

Compliance of the compatibility in the finite element stiffness method is illustrated by considering the example of a plane stress elasticity problem. The field compatibility condition $\left(\frac{\partial^{2} \varepsilon_{x}}{\partial y^{2}}+\frac{\partial^{2} \varepsilon_{y}}{\partial x^{2}}-\frac{\partial^{2} \gamma_{x y}}{\partial x \partial y}=0\right)$, when expressed in terms of continuous displacement variables $u$ and $v$ produces a trivial condition (or an identity $\{f(u, v)-f(u, v)=0\}$. The field compliance is well recognized in the stiffness method. The boundary compatibility condition expressed in terms of strains has the following form:

$$
a_{v x} \frac{\partial}{\partial x} \varepsilon_{y}+a_{v y} \frac{\partial}{\partial y} \varepsilon_{x}-\frac{1}{2}\left[a_{v x} \frac{\partial}{\partial x} \gamma_{x y}+a_{v y} \frac{\partial}{\partial y} \gamma_{x y}\right]=0
$$

When expressed in terms of continuous displacements $u$ and $v$ the boundary compatibility condition becomes a nontrivial function as follows:

$$
\Re=a_{v x}\left[\frac{\partial^{2} v}{\partial x \partial y}-\frac{1}{2}\left(\frac{\partial^{2} v}{\partial x^{2}}+\frac{\partial^{2} u}{\partial x \partial y}\right)\right]+a_{v y}\left[\frac{\partial^{2} u}{\partial x \partial y}-\frac{1}{2}\left(\frac{\partial^{2} u}{\partial y^{2}}+\frac{\partial^{2} v}{\partial x \partial y}\right)\right] \neq 0
$$

The boundary compatibility condition expressed in terms of the displacement is not automatically satisfied. Consider a simple finite element model with a four-node rectangular element and a three-node triangular element, as shown in Fig. 4. Along the interface connecting nodes 2 and 4 the compliance of the boundary compatibility can be imposed by the following residue function:

$$
\mathfrak{h}^{\text {interface }}=\mathfrak{l}^{\text {rectangular element }}+\mathfrak{h}^{\text {triangular element }}=0
$$

Consider displacement functions for the rectangular and triangular membrane elements (ref. 21) as follows:

For a rectangular element

$$
\text { rectangular } u(x, y)=c_{1} x+c_{2} x y+c_{3} y+c_{4}
$$

Likewise the rectangular $v(x, y)$ can be written. The eight constants $\left(c_{1}, c_{2}, \ldots, c_{8}\right)$ can be linked to the eight nodal displacements of the rectangular element. 
For a triangular element

$$
{ }_{\text {triangular }} u(x, y)=d_{1} x+d_{2} y+d_{3}
$$

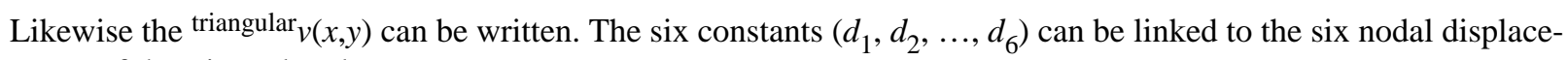
ments of the triangular element.

The contribution to the residue function $\gtrsim$ for each of the two elements can be obtained as follows:

$$
\begin{gathered}
\Re^{\text {element-rectangular-(2-4) }}=0.5\left\{a_{v x} c_{6}+a_{v y} c_{2}\right\} \\
\Re^{\text {element-triangular-(2-4) }}=0
\end{gathered}
$$

Thus, the boundary compliance $\left(\varkappa^{\text {rectangular element }}+\Re^{\text {triangular element }} \neq 0\right)$ at the interface of the finite element model shown in Fig. 4 is not satisfied.

In the finite element analysis the traditional assumption that the stiffness method satisfies the compatibility condition a priori needs to be reviewed with respect to compliance of the boundary compatibility conditions. In the stiffness method continuity is imposed on the nodal displacements (such as, for example, at nodes 2 and 4 in Fig. 4). The displacement continuity condition can not be sufficient for the compliance of the boundary compatibility condition in the interface (generated by nodes 2 and 4 in Fig. 4).

\section{BENEFITS FROM COMPATIBILITY CONDITIONS}

In this paper we discuss the benefits gained from using the compatibility conditions in finite element analysis. Similar benefits in continuum analysis (refs. 16, 17, and 22), design optimization, and structural testing are described in references 12,23 , and 24 . To quantify the benefit, we have developed a research-level finite element code entitled IFM/Analyzers. This code provides for three analysis methods: integrated force method, dual integrated force method, and stiffness method. The IFM and IFMD equations, programmed in IFM/Analyzers code, are summarized next.

\section{Equations of Integrated Force Method for Static Analysis}

The IFM equations for a finite element model with $n$ force and $m$ displacement unknowns are obtained by coupling the $m$ equilibrium equations $([\mathbf{B}]\{F\}=\{P\})$ to the $r=n-m$ compatibility conditions $([\mathbf{C}][\mathbf{G}]\{F\}=\{\delta R\})$ :

$$
\left[\frac{[\mathbf{B}]}{[\mathbf{C}][\mathbf{G}]}\right]\{F\}=\left\{\frac{\{P\}}{\{\delta R\}}\right\} \quad \text { or } \quad[\mathbf{S}]\{F\}=\left\{P^{*}\right\}
$$

From the internal forces $\{F\}$ the displacements $\{X\}$ are backcalculated as

$$
\{X\}=[\mathbf{J}]\left\{[\mathbf{G}]\{F\}+\left\{\beta^{0}\right\}\right\}
$$

where $[\mathbf{J}]=m$ rows of $\left\{[\mathbf{S}]^{-1}\right\}^{T}$

In equations (26 and 27) [B] is the $m \times n$ rectangular equilibrium matrix, [G] is the $n \times n$ flexibility matrix, [C] is the $r \times n$ compatibility matrix, $\{\delta R\}=-[\mathbf{C}]\left\{\beta^{0}\right\}$ is the $r$-component effective initial deformation vector, $\left\{\beta^{0}\right\}$ is the initial deformation vector of dimension $n$, [S] is the IFM governing matrix, and $[\mathbf{J}]$ is the $m \times n$ deformation coefficient matrix. The IFM matrices and vectors are generated in references 25 and 26. 


\section{Equations of Dual Integrated Force Method for Static Analysis}

A dual formulation of the primal IFM has been developed. The dual integrated force method has been obtained by mapping forces into displacements at the element level. Like the IFM the dual method has two sets of equations. The primary set is used to calculate the displacements. Forces are backcalculated from the secondary set of equations. IFM and IFMD are analytically equivalent—producing identical solutions for stress, displacement, frequency, and buckling load. The IFMD governing equations are

$$
\begin{gathered}
{[\mathbf{K}]_{m \times m} \underset{m \times 1}{ }\{X\}=\{P\}_{\text {IFMD }}} \\
\{F\}=[\mathbf{G}]^{-1}[\mathbf{B}]^{T}\{X\}-[\mathbf{G}]^{-1}\{\beta\}^{0}
\end{gathered}
$$

where

$$
\begin{gathered}
{[\mathbf{K}]_{\mathrm{IFMD}}=[\mathbf{B}][\mathbf{G}]^{-1}[\mathbf{B}]^{T}} \\
\{P\}_{\mathrm{IFMD}}=\left\{\{P\}+\left([\mathbf{B}][\mathbf{G}]^{-1}\{\beta\}^{0}\right)\right\}
\end{gathered}
$$

The IFMD primary equations and the stiffness method equations appear to be similar, but the coefficients of the stiffness matrix and that of the dual matrix $[\mathbf{K}]_{\mathrm{IFMD}}$ differ in magnitude (ref. 10).

\section{Numerical Examples}

The numerical examples presented use three elements of the IFM/Analyzers code: (1) a quadrilateral membrane element, QUAD0405; (2) a hexagonal solid element, HEX2090; and (3) a plate flexure element, PLB0409. The generation of the elemental equilibrium matrix $\left[\mathbf{B}^{e}\right]$ in IFM uses both the force and displacement fields, even though the final equation is expressed in terms of elemental forces $\left(\left[\mathbf{B}^{e}\right]\left\{F^{e}\right\}=\left\{P^{e}\right\}\right)$. The role of the displacement field in $\left[\mathbf{B}^{e}\right]$ resembles the concept of virtual displacement. The generation of the elemental matrices uses numerical integration but does not use reduced integration or bubble function techniques. In the numerical examples the performance of the simple IFM elements is compared with that of the popular stiffness elements. The basic attributes of the IFM elements are

1. QUAD0405: This is a four-node element with two displacements ( $u$ and $v)$ and three stresses $\left(\sigma_{x}, \sigma_{y}\right.$, and $\left.\tau_{x y}\right)$. The element has eight displacement degrees of freedom. Five force unknowns represent the discretization of the three stresses $\left(\sigma_{x}, \sigma_{y}\right.$, and $\left.\tau_{x y}\right)$. Normal stresses $\sigma_{x}$ and $\sigma_{y}$ vary linearly while the shear stress $\tau_{x y}$ is constant.

2. HEX2090: This is a 20-node element with three displacements $(u, v$, and $w)$ and six stresses $\left(\sigma_{x}, \sigma_{y}, \sigma_{z}, \tau_{x y}\right.$, $\tau_{x z}$, and $\tau_{y z}$. Displacements are discretized to obtain 60 degrees of freedom. All six stress components are represented by 90 force unknowns.

3. PLB0409: This is a four-node plate bending element with transverse displacement $w$ and three moments $\left(M_{x}\right.$, $M_{y}$, and $\left.M_{x y}\right)$. The displacement is discretized to obtain 12 degrees of freedom. All three moments are represented by nine force unknowns.

Numerical example 1: cantilever beam modeled by membrane elements.-The cantilever beam shown in Fig. 5(a) is 24 in. long, 2 in. deep, and 0.25 in. thick. It is made of steel with Young's modulus of $30 \times 10^{6}$ psi and Poisson's ratio of 0.30 and is subjected to 200-lb load at its free end. The beam was modeled with the QUAD0405 element of IFM/Analyzers and the CQUAD4 element of a popular commercial code. The stiffness elements (CQUAD4 of the commercial code and QUAD0405 of IFM/Analyzers) supported the linear stress field along the 
beam depth. Thus, only discretization along the beam length was considered, which, however, is the standard practice for comparison (ref. 27). The solution for the tip displacement normalized with respect to material strength is depicted in Fig. 5(b). The error in the displacement for a four-element model obtained by IFM/Analyzers was 1.1 percent versus 10 percent for the commercial code. For an eight-element model the error was reduced to zero by IFM. The converged commercial code solution exhibited an error of about 9 percent even for a dense model with 48 elements. For this example a converged solution by the commercial stiffness code was found to be incorrect.

Numerical example 2: cantilever beam modeled by solid elements.-The cantilever beam shown in Fig. 6(a) is $12 \mathrm{in.} \mathrm{long,} 1$ in. deep, and 1 in. thick. It is made of steel with Young's modulus of $30 \times 10^{6}$ psi and Poisson's ratio of 0.30 and is subjected to $10-\mathrm{lb}$ load at its free end. The beam was modeled with hexahedral elements. For IFM/ Analyzers the HEX2090 element was used. A 20-node CHEXA element was used for the commercial code. The displacement, frequency, and stress solutions for different finite element models are given in Figs. 6(b) and (c). The maximum displacement and fundamental frequency generated by IFM and the commercial code converged at about the same rate. Difficulty was encountered for stress convergence. The stress patterns generated by IFM and the stiffness method looked similar. However, against a 720-psi beam solution, IFM converged to 630 psi, but the stiffness method could produce only 356 psi for a six-element model.

Numerical example 3: a plate flexure problem.-A rectangular clamped plate, shown in Fig. 7(a), subjected to a concentrated load of $1000 \mathrm{lb}$, was solved by using the PLB0409 element of IFM/Analyzers and by the CQUAD4 element of a commercial code. The plate is made of steel with Young's modulus of $30 \times 10^{6} \mathrm{psi}$ and Poisson's ratio of 0.30. Its dimensions ( $a, b$, and thickness $t$, see Fig. 7) are 24, 12, and 0.25 in., respectively. Results normalized with respect to Timoshenko's solutions (ref. 18) are depicted in Figs. 7(b) and (c). The central displacement obtained by IFM achieved an accuracy of 98.7 percent for a model with eight elements. For a coarser model with only four elements the error was about 17.5 percent. The solution obtained by the commercial code required 64 elements to achieve an accuracy of 98 percent. The performance of a second commercial code followed the pattern of the first code with some variation. For the bending moment convergence occurred with the PLB0409 element, using a model with four elements per quarter plate. For a model with one element per quarter plate the IFM solution exhibited a 20 percent error. For the commercial code the bending moment exhibited an error of about 7 percent even for a fine model with 16 elements per quarter plate.

For the three examples the integrated force method outperformed the stiffness method, overshadowing the simplicity at the element level.

\section{DISCUSSION}

The discussion is separated into the completeness of the theory, the quality of analytical predictions, and the near-term research.

\section{Completeness of Theory}

The theory of structures began before the birth of Newton in the notebooks of Leonardo da Vinci and through Galileo Galilei's studies on structures (ref. 1). The growth accelerated during the nineteenth century as the eminent scientists and engineers Cauchy, Navier, Saint-Venant, Castigliano, and others worked on different applications (see Fig. 8). It was commonly believed that all fundamental concepts of this four-century-old science were fully understood before the turn of the twentieth century. This belief was not correct. The traditional theory of compatibility camouflaged a deficiency described in this paper.

If the compatibility conditions were not required, the theory of (determinate) structures could be covered in a few undergraduate courses. Satisfying the compatibility conditions makes the theory a research topic practiced at doctoral and postdoctoral levels around the world. Here we digress to speculate on the possible reasons for the tardy incorporation of the compatibility conditions into the theory of structures.

The compatibility conditions are more complex relationships than the equilibrium equations. However, it is not likely that their complexity would have been an insurmountable obstacle for Cauchy, Saint-Venant, Navier, or Maxwell (see Fig. 8). 
Complacency could be another possible reason, but observed inconsistencies between different approaches to the solution of indeterminate problems suggest that this could not have been the primary reason. For example, displacements are the unknowns in the displacement method, but redundants, instead of forces, became the unknowns in the traditional force method. Also, the displacement method could solve all three types of boundary value problems in elasticity, but the Beltrami-Michell formulation could handle only stress boundary value problems. The redundant force method in structures did not parallel the Beltrami-Michell formulation in elasticity. Even novice researchers would surely have noticed and questioned the lack of uniformity between the methods in elasticity and structures.

Often an approximate solution was adequate to fulfill the need of an industry that may have had little interest in the particular method used. Take, for example, the building and bridge industries, which require analysis of indeterminate trusses, continuous beams, frames, and other structures. The redundant force method solved such problems. For plates and shells solutions obtained through the superposition technique served the industry well. Solving engineering problems not only became central to the work but also occupied most of the available time of competent researchers, leaving little or no time for them to ponder or address the deficiencies and completion of the theory of compatibility. The engineering problem-solving aspect of structural mechanics was considered to be the most important. The dividends associated with solving industrial problems are, in our opinion, the primary reason behind the slow progress of the compatibility conditions. Complexity and complacency may be considered but secondary reasons.

It is important to evaluate the completeness of the theory of structures as a science, as opposed to merely solving industrial problems. The current acceptance of the stiffness solution by industry should not lead to neglect of the discipline, which may have entered a developmental plateau. Research on compatibility can reinvigorate the structures discipline and eventually provide a robust alternative formulation for solving industrial structures problems.

\section{Quality of Analytical Prediction}

The quality of analytical predictions can be directly controlled by imposing the requirement that the equilibrium equations and the compatibility conditions be simultaneously satisfied. The discretization error can be reduced through mesh refinement. The integrated force method adopts this approach and produces accurate solutions even when the structure is modeled with a modest size of finite element mesh. Even though emphasis on and clever manipulation of one of the two equation sets may appear to be adequate for the analysis of some problems, the reliability of the solution thus obtained cannot always be guaranteed. For example, the monotonically converged stiffness solution in Fig. 5 was erroneous.

Consider next a deficiency observed by Thodhunter (ref. 28) while he was scrutinizing Astronomer Royal Airy's attempt to analyze the stress in cantilever and simply supported beams. Airy formulated a potential function to satisfy the equilibrium equations. He manipulated the equilibrium equations and the boundary conditions to generate the solution for the examples. However, his results were incorrect because he neglected the compatibility compliance. Thodhunter (ref. 28) describes the situation:

Important Addition and Correction. The solution of the problems suggested in the last two Articles were given — as has already been stated — on the authority of a paper by the late Astronomer Royal, published in a report of the British Association. I now observe, however-when the printing of the articles and engraving of the Figures is already completed - that they cannot be accepted as true solutions, inasmuch as they do not satisfy the general equations (164) of $\S 303$ [note that the equations in question are the compatibility conditions]. It is perhaps as well that they should be preserved as a warning to the students against the insidious and comparatively rare error of choosing a solution which satisfies completely all the boundary conditions, without satisfying the fundamental condition of strain [note that the condition in question is the compatibility condition], and which is therefore of course not a solution at all.

The advice of Thodhunter should be followed to generate solutions by simultaneously satisfying all the equilibrium equations and all the compatibility conditions. 


\section{Near-Term Research}

Equilibrium and compatibility constitute the two fundamental equations of the theory of structures, as depicted in the two halves of the pie diagram in Fig. 9. The immaturity in the compatibility conditions is represented by the shaded quarter. The theory of structures has been developed by using the information contained in three-quarters of the pie diagram. Using the additional quarter should improve the theory and the performance of the analysis methods. Near-term research should address at least two issues: unification of the theory, and compliance of the boundary compatibility conditions.

Unification of theory.-Using the compatibility conditions can lead to the unification of the theory of structures, allowing free movement between different analysis variables as well as the various methods of structural analysis. In discrete element analysis we can move from displacement to stress through a set of algebraic equations and vice versa. Likewise we should be able to move from force method to displacement method. For example, we can move from the integrated force method to the dual integrated force method, both methods yielding identical solutions. Even though the IFM and IFMD produce identical solutions, each method has unique attributes. The primal IFM is more suited to design optimization because this method generates closed-form sensitivities for stress, displacement, and frequency constraints (ref. 12). An analytical initial design to begin optimization iteration can be obtained by IFM (ref. 29). Singularity in optimization and behavior of constraints are elegantly treated by IFM (refs. 30 to 32). The dual IFMD is not as suitable as the primal IFM for design calculations. The governing matrix of IFMD is symmetrical. Therefore, IFMD can use solvers that have been obtained for the stiffness method. This approach should be extended for continuum analysis, reducing any barrier between elasticity and structures. For example, the force method concept should be consistent between structures and elasticity (like the integrated force method and the completed Beltrami-Michell formulation).

Satisfaction of boundary compatibility conditions. - The traditional solutions and other analysis methods must be checked for the compliance of the boundary compatibility conditions. Compliance of the BCC at the element interface in the stiffness-method-based finite element analysis should be reviewed. The stiffness elements, if necessary, should be modified for the compliance of the BCC.

\section{CONCLUSIONS}

The theory of structures has concealed a deficiency that has been present in the compatibility conditions since Saint-Venant's strain formulation in 1860 . We have researched and addressed these important conditions in structures and elasticity.

Because of the compatibility deficiency the direct methods (integrated force method in structures and completed Beltrami-Michell formulation in elasticity) that bestow simultaneous emphasis on stress equilibrium and strain compatibility were not available during the formative 1960's. Despite the deficiency structural analysis has made magnificent progress through the stiffness method. However, in academia research into the stiffness method has entered a developmental plateau. Bringing back the method of forces can reinvigorate the discipline and provide a robust alternative formulation for solving industrial structural problems.

We can more precisely quantify the accuracy of predictions by comparing the force and stiffness method solutions and balance the monopoly that is currently biased toward the stiffness method. The new methods can bring value-added benefits in structural analysis, structural design, and structural testing.

\section{REFERENCES}

1. G. Galilei, Dialogues Concerning Two New Sciences, Northern University Press, Evanston, Illinois, 1950.

2. P.H. Denke, A General Digital Computer Analysis of Statically Indeterminate Structures, NASA TN D-1666, 1962.

3. J. Robinson, Automatic Selection of Redundancies in the Matrix Force Method: The Rank Technique, Canadian Aeronautics J., 11, 9-12 (1965). 
4. A.E.H. Love, A Treatise on the Mathematical Theory of Elasticity, Fourth ed., Dover Publications, New York, 1944, pp. 17, para. 1.

5. S.N. Patnaik, The Variational Energy Formulation for the Integrated Force Method, AIAA J., 24, $129-137$ (Jan. 1986).

6. I. Kaljevic, D.A. Hopkins, S. Saigal, and S.N. Patnaik, Completed Beltrami-Michell Formulation for Analyzing Mixed Boundary Value Problems in Elasticity, AIAA J., 34, 1, 143-148 (1996).

7. S.N. Patnaik, L. Berke, and R.H. Gallagher, Compatibility Conditions of Structural Mechanics for Finite Element Analysis, AIAA J., 29, 820-829 (May 1991).

8. S.N. Patnaik, L. Berke, and R.H. Gallagher, Integrated Force Method Versus Displacement Method for Finite Element Analysis, Computers \& Structures, 38, 4, 377-407 (1991).

9. S.N. Patnaik, R.M. Coroneos, and D.A. Hopkins, Dynamic Animation of Stress Modes via the Integrated Force Method of Structural Analysis, Int. J. Numer. Meth. Engrg., 40, 12, 2151-2169 (1997).

10. S.N. Patnaik, D.A. Hopkins, R.A. Aiello, and L. Berke, Improved Accuracy for Finite Element Structural Analysis via an Integrated Force Method, Computers \& Structures, 45, 3, 521-542 (1992).

11. S.N. Patnaik, Integrated Force Method Versus the Standard Force Method, Computers \& Structures, 22, 2 , 151-163 (1986).

12. S.N. Patnaik and R.H. Gallagher, Gradients of Behaviour Constraints and Reanalysis via the Integrated Force Method, Int. J. Numer. Meth. Engrg., 23, 2205-2212 (Dec. 1986).

13. O.C. Zienkiewicz, The Finite Element Method, McGraw-Hill, New York, 1977.

14. R.H. Gallagher, Finite Element Analysis: Fundamentals, Prentice-Hall, Englewood Cliffs, New Jersey, 1975.

15. J.H. Argyris and S. Kesley, Matrix Force Method of Structural Analysis With Applications to Aircraft Wings, Wissenschaften Gessellschaft Luftfahrt, 1956, pp. 78-98.

16. S.N. Patnaik and M.S. Nagaraj, Analysis of Continuum by the Integrated Force Method, Computers \& Structures, 26, 6, 899-905 (1987).

17. K. Vijayakumar, A.V. Krishna Murty, and S.N. Patnaik, A Basis for the Analysis of Solid Continua Using the Integrated Force Method, AIAA J., 26, 628-629 (May 1988).

18. S. Timoshenko and S. Woinowsky-Krieger, Theory of Plates and Shells, McGraw-Hill, New York, 1959.

19. I.S. Sokolnikoff, Mathematical Theory of Elasticity, Second ed., McGraw-Hill, New York, 1956.

20. K. Washizu, Variational Methods in Elasticity and Plasticity, Second ed., Pergamon Press, New York, 1975.

21. J.S. Przemieniecki, Theory of Matrix Structural Analysis, McGraw-Hill, New York, 1968.

22. S.N. Patnaik and H.G. Satish, Analysis of Continuum Using the Boundary Compatibility Conditions of Integrated Force Method, Computers \& Structures, 34, 2, 287-295 (1990).

23. S.N. Patnaik, A.S. Gendy, L. Berke, and D.A. Hopkins, Modified Fully Utilized Design Method (MFUD) for Stress and Displacement Constraints, Int. J. Num. Meth. Engrg., 41, 7, 1171-1194 (1998).

24. S.N. Patnaik, D.A. Hopkins, and R. Coroneos, Structural Optimization With Approximate Sensitivities, Computers \& Structures, 58, 407-418 (1996). (Also NASA TM-4553.)

25. I. Kaljevic, S.N. Patnaik, and D.A. Hopkins, Development of Finite Elements for Two-Dimensional Structural Analysis Using the Integrated Force Method, Computers \& Structures, 59, 4, 691-706 (1996).

26. I. Kaljevic, S.N. Patnaik, and D.A. Hopkins, Three-Dimensional Structural Analysis by the Integrated Force Method, Computers \& Structures, 58, 5, 869-886 (1996).

27. R.L. Spilker, S.M. Maskeri, and E. Kania, Plane Isoparametric Hybrid-Stress Elements: Invariance and Optimal Sampling, Int. J. Numer. Meth. Engrg., 17, 10, 1469-1496 (1981).

28. I. Thodhunter, A History of the Theory of Elasticity and of the Strength of Materials, From Galilei to the Present Time, University Press, K. Pearson, ed., Cambridge, England, pp. 1886-1893.

29. S.N. Patnaik, Analytical Initial Design for Structural Optimization via the Integrated Force Method, Computers \& Structures, 33, 7, 265-268 (1989).

30. S.N. Patnaik, J.D. Guptill, and L. Berke, Singularity in Structural Optimization, Int. J. Numer. Meth. Engrg., 36, 6, 931-944 (1993).

31. S.N. Patnaik and P. Dayaratnam, Behavior and Design of Pin-Connected Structures, Int. J. Numer. Meth. Engrg., 12, 579-595 (1972).

32. P. Dayaratnam and S.N. Patnaik, Feasibility of Full Stress Design, AIAA J., 7, 773-774 (1969). 
TABLE I_-METHODS OF STRUCTURAL MECHANICS AND ASSOCIATED VARIATIONAL FUNCTIONALS

\begin{tabular}{|c|l|l|l|l|l|}
\hline \multirow{2}{*}{$\begin{array}{c}\text { Method } \\
\text { number }\end{array}$} & \multicolumn{1}{|c|}{ Method } & \multicolumn{1}{c|}{ Primary variable } & \multicolumn{1}{c|}{$\begin{array}{l}\text { Variational } \\
\text { functional }\end{array}$} \\
\hline 1 & $\begin{array}{l}\text { Completed } \\
\text { Beltrami-Michell } \\
\text { formulation }\end{array}$ & $\begin{array}{l}\text { Integrated force } \\
\text { method }\end{array}$ & Stress & Force & $\begin{array}{l}\text { IFM variational } \\
\text { functional }\end{array}$ \\
\hline 2 & Airy formulation & $\begin{array}{l}\text { Redundant force } \\
\text { method }\end{array}$ & Stress function & Redundant & $\begin{array}{l}\text { Complementary } \\
\text { energy }\end{array}$ \\
\hline 3 & Navier formulation & Stiffness method & Displacement & Deflection & Potential energy \\
\hline 4 & Hybrid method & Reissner method & $\begin{array}{l}\text { Stress and } \\
\text { displacement }\end{array}$ & Force and deflection & Reissner functional \\
\hline 5 & Total formulation & Washizu method & $\begin{array}{l}\text { Stress, strain, and } \\
\text { displacement }\end{array}$ & $\begin{array}{l}\text { Force, deformation, } \\
\text { and deflection }\end{array}$ & Washizu functional \\
\hline
\end{tabular}

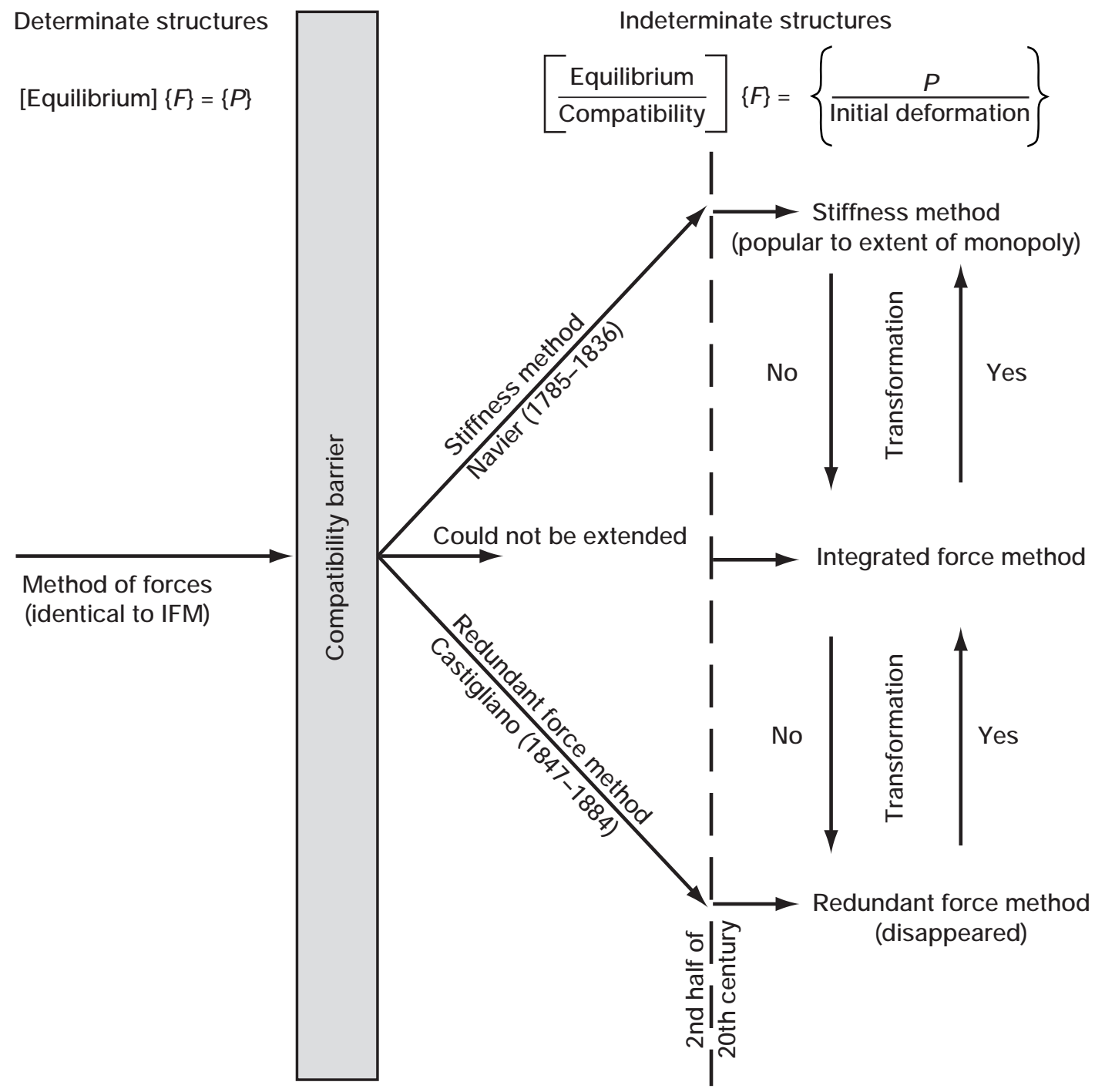

Figure 1.-Compatibility barrier to extending force method for indeterminate structures. 


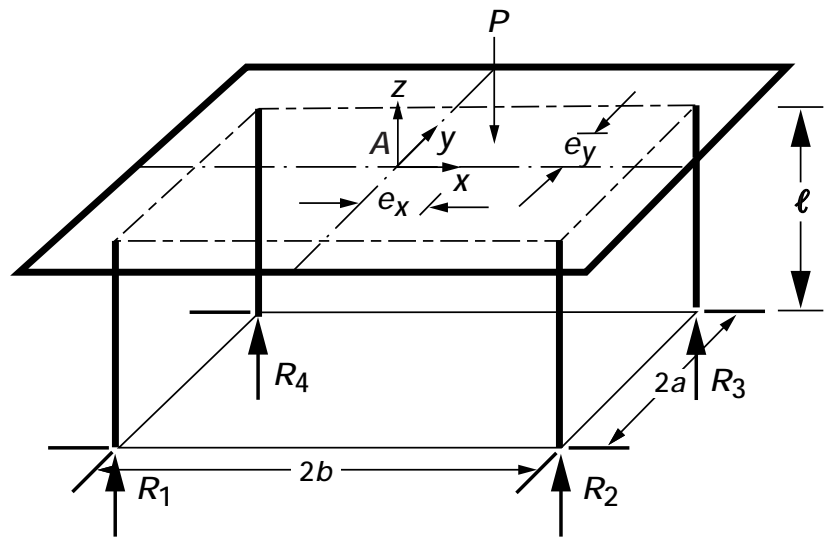

(a)

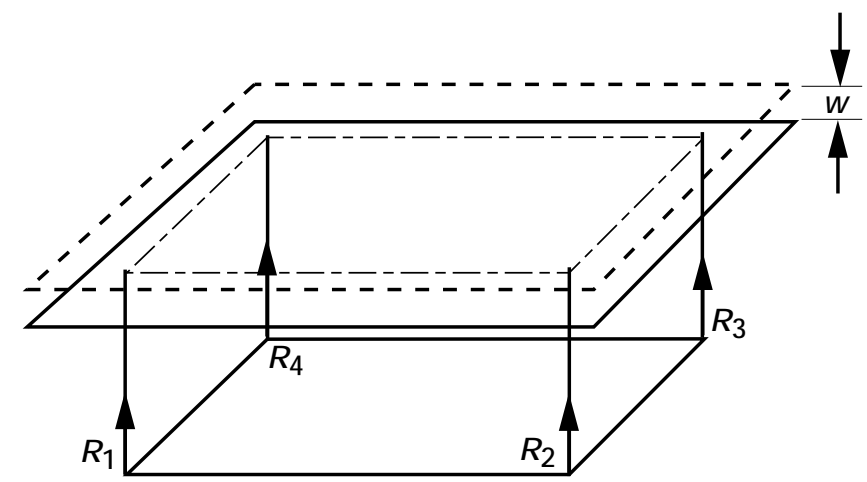

(b)

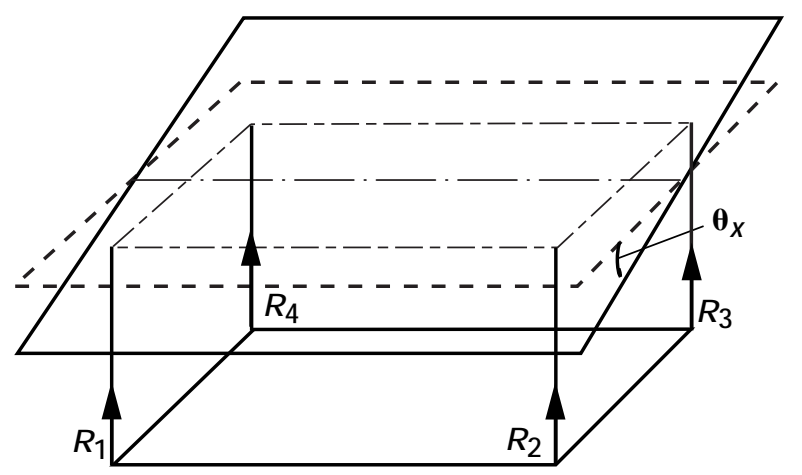

(c)

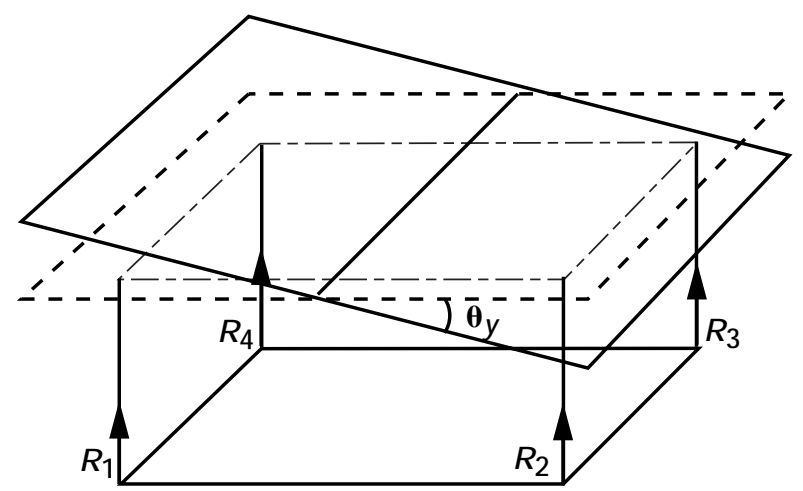

(d)

Figure 2.- IFM solution to Navier's table problem. (a) Indeterminate table problem. (b) Average displacement along z-axis. (c) Average tilt about $x$-axis. (d) Average tilt about y-axis. 

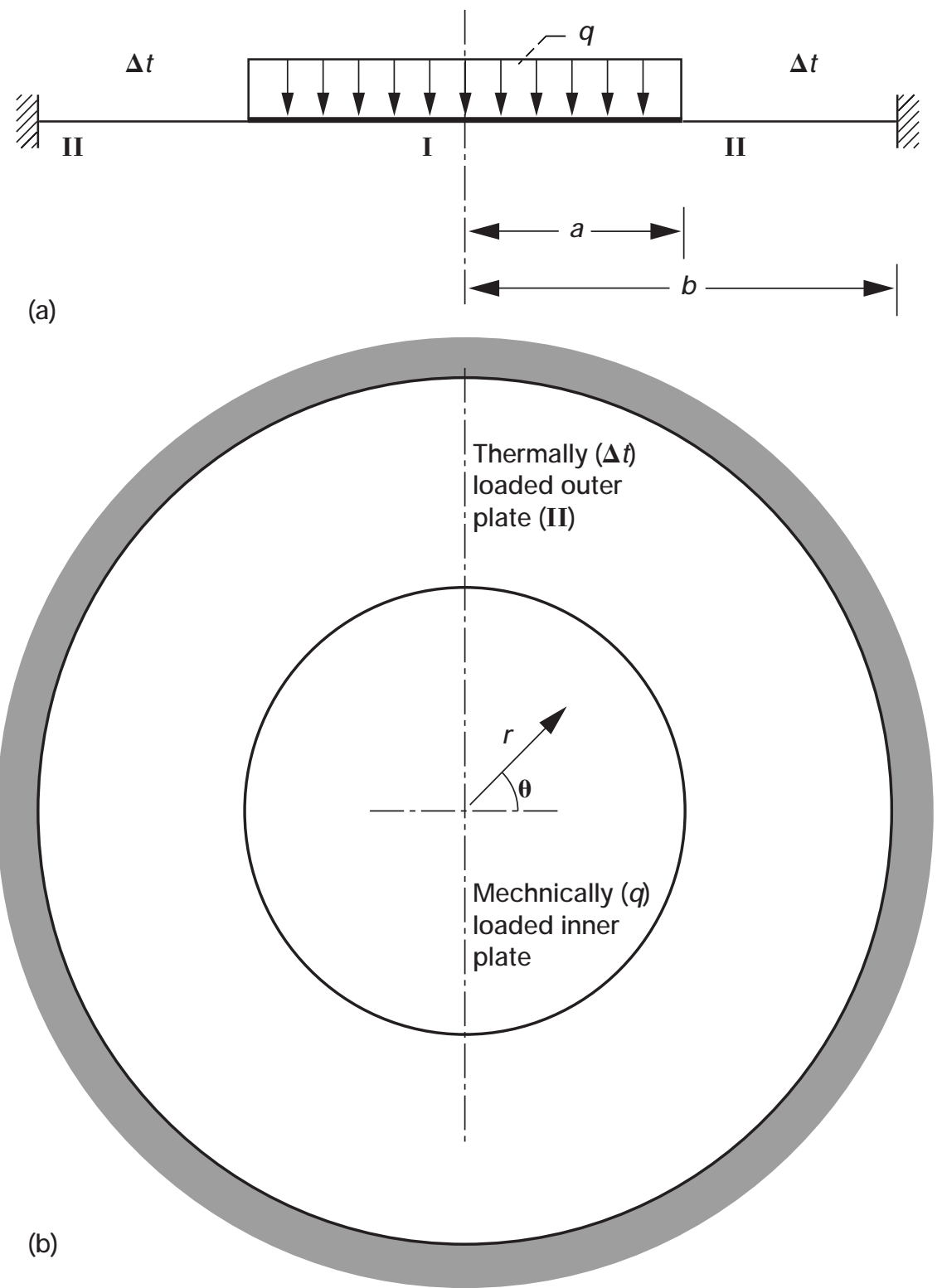

Figure 3.-Composite circular plate subjected to uniform load $q$ and temperature differential $\Delta t$. (a) Side view of plate. (b) Planform of plate. 


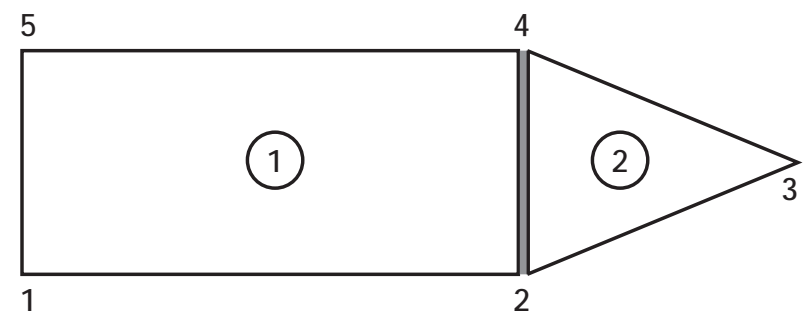

Figure 4.- Boundary compatibility compliance for two-element model.
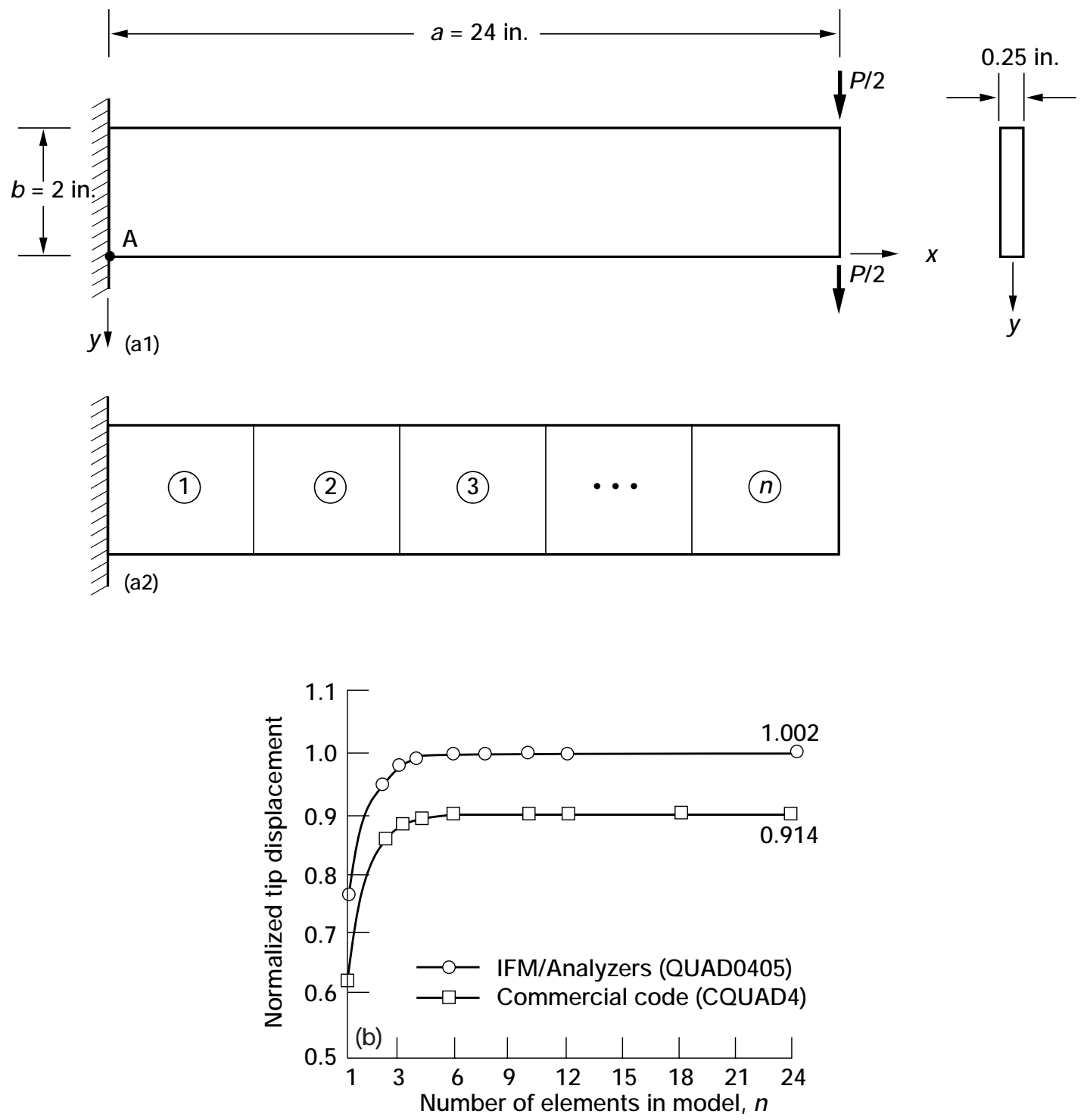

Figure 5.- Numerical example 1: Analysis of cantilever beam. (a1) Geometry and boundary conditions. (a2) Finite element model. (b) Convergence of cantilever beam tip displacement. 


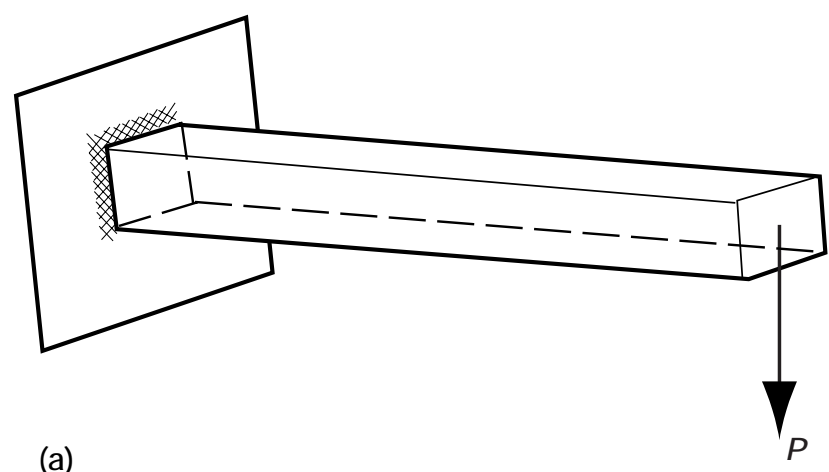

\begin{tabular}{|l|r|c|c|c|}
\hline \multirow{2}{*}{ Model } & \multicolumn{2}{|c|}{$\begin{array}{c}\text { Normalized } \\
\text { displacement }\end{array}$} & \multicolumn{2}{c|}{ Frequency } \\
\cline { 2 - 5 } & $\begin{array}{c}\text { IFM/ } \\
\text { IFMD }\end{array}$ & $\begin{array}{c}\text { Commercial } \\
\text { code }\end{array}$ & $\begin{array}{c}\text { IFM/ } \\
\text { IFMD }\end{array}$ & $\begin{array}{c}\text { Commercial } \\
\text { code }\end{array}$ \\
\hline $2 \times 1 \times 1$ & 0.802 & 0.790 & 1.198 & 1.182 \\
$3 \times 1 \times 1$ & .956 & .949 & 1.037 & 1.032 \\
$4 \times 1 \times 1$ & .985 & .979 & 1.012 & 1.008 \\
$5 \times 1 \times 1$ & .993 & .988 & 1.005 & 1.000 \\
$6 \times 1 \times 1$ & .996 & .991 & 1.003 & 1.000 \\
$7 \times 1 \times 1$ & .997 & .993 & 1.002 & .999 \\
$7 \times 2 \times 2$ & .995 & .995 & 1.001 & 1.001 \\
$7 \times 4 \times 4$ & .997 & .996 & 1.001 & 1.010 \\
\hline
\end{tabular}

(b)

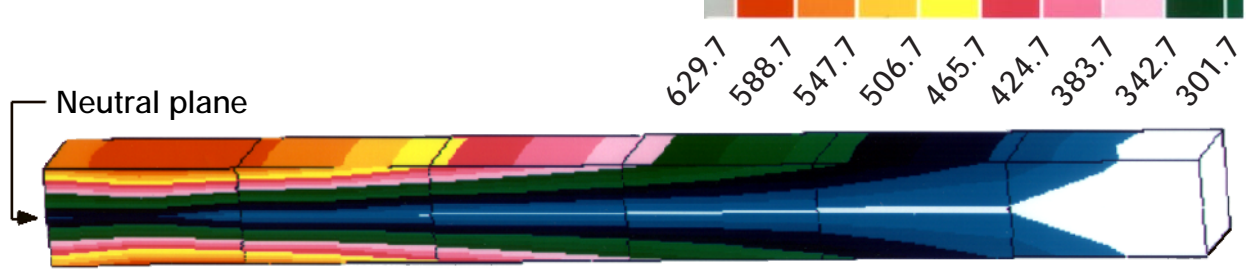

(c1)

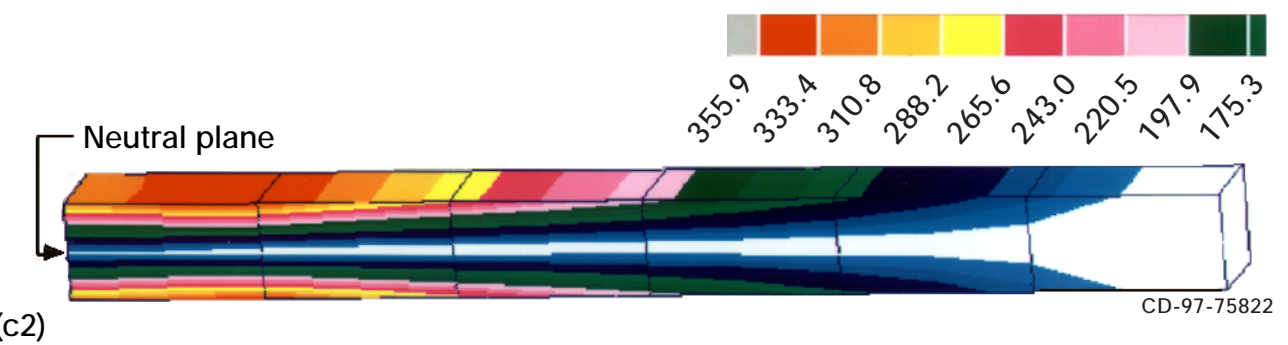

Figure 6.- Numerical example 2: Stress analysis of cantilever beam. (a) Geometry.

(b) Displacement and frequency solution. (c) Stress solution. (c1) IFM/IFMD: stress, 629.7 psi. (c2) Commercial code: stress, 355.9 psi. 


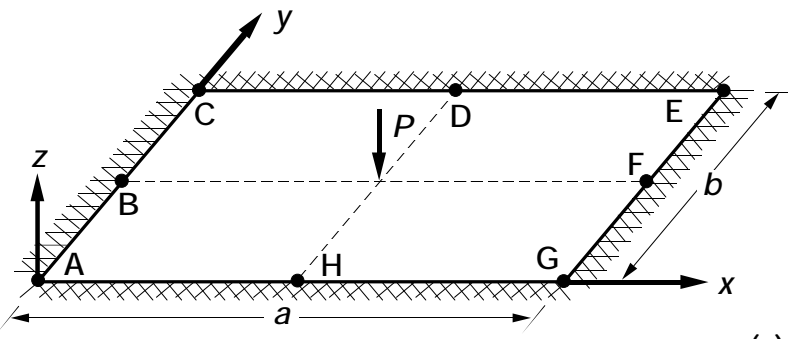

(a)
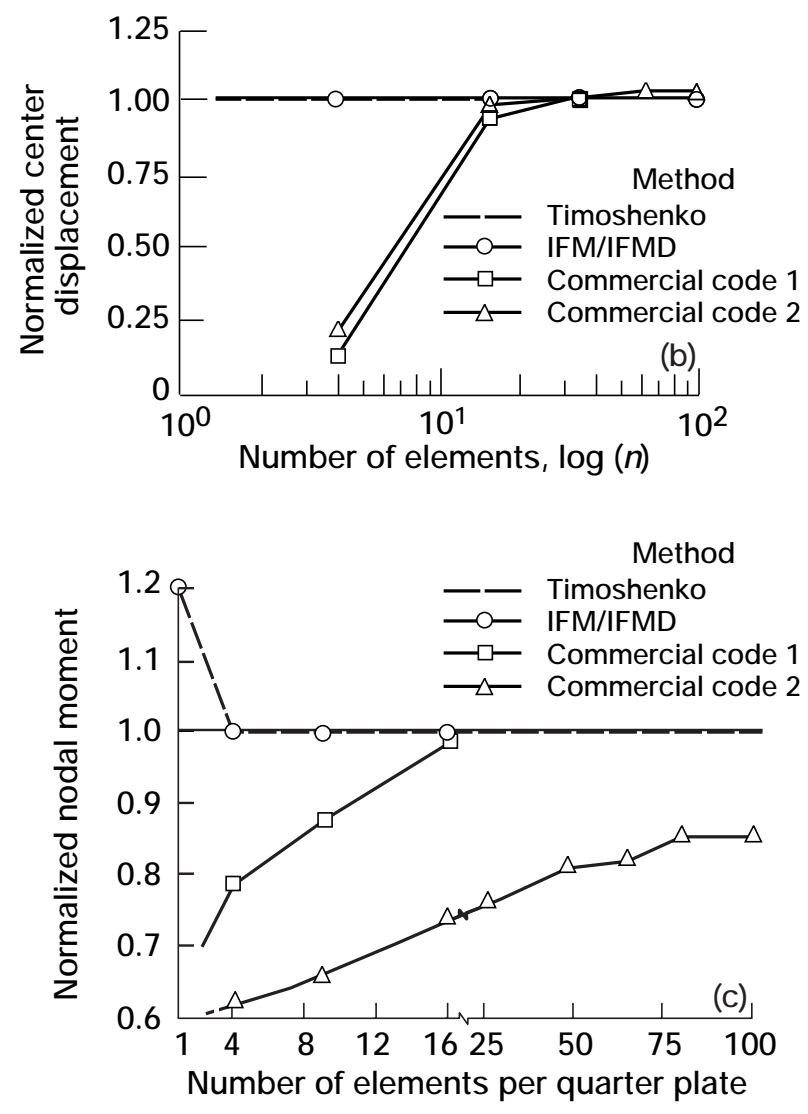

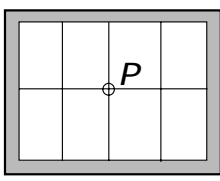

IFM/IFMD

secured

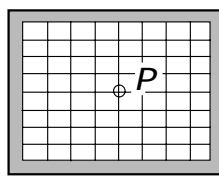

Commercial code 1 , secured grade $A$; Commercial code 2 , secured grade $B$
Grade Error, percent

A $<2$

B $>2$ but $<10$

Figure 7.- Numerical example 3: Analysis of clamped plate. (a) Geometry. (b) C onvergence of displacement. (c) Convergence of stress. (d) Finite element models. 


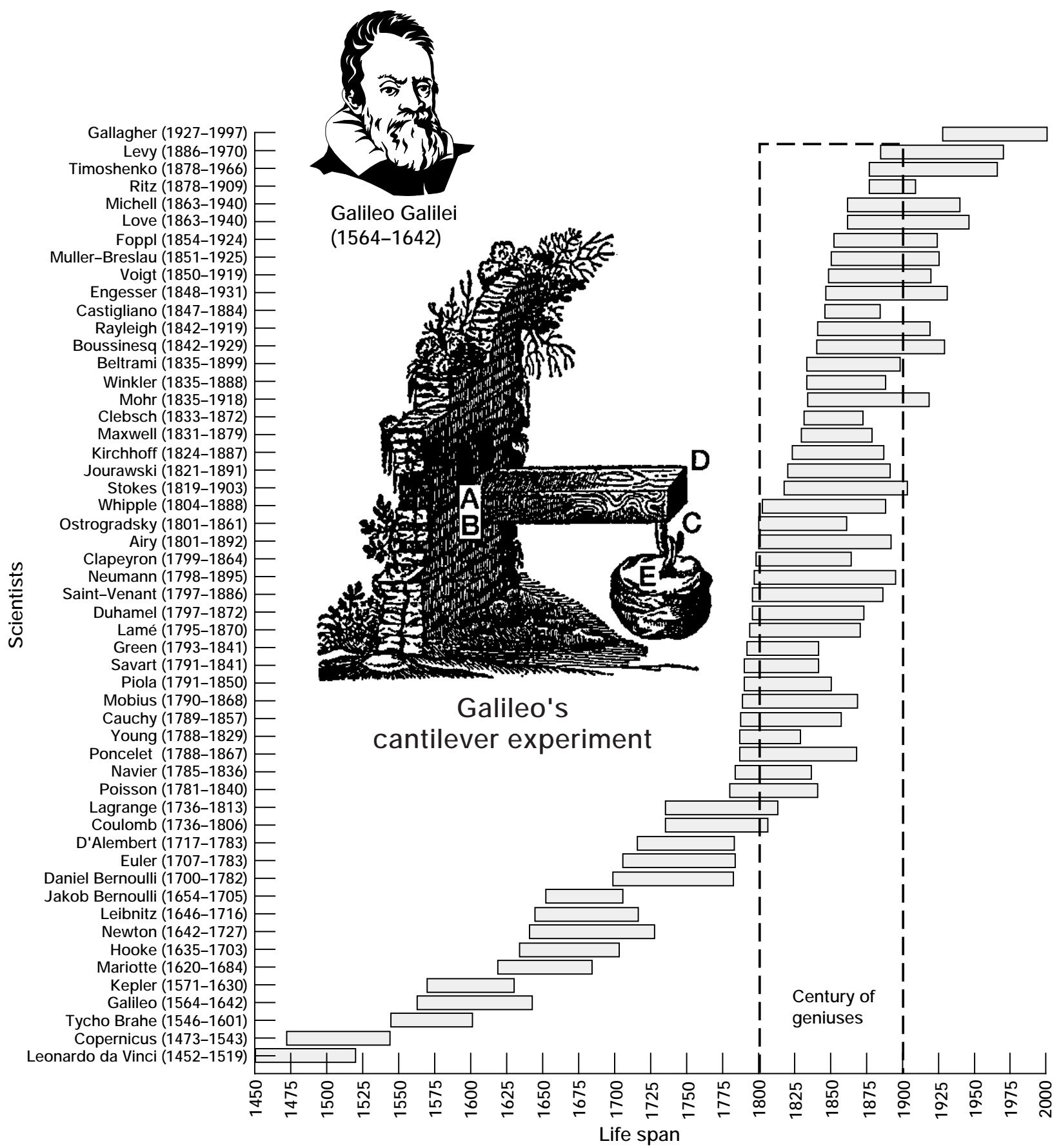

Figure 8.- Scientists who contributed to structural science. 


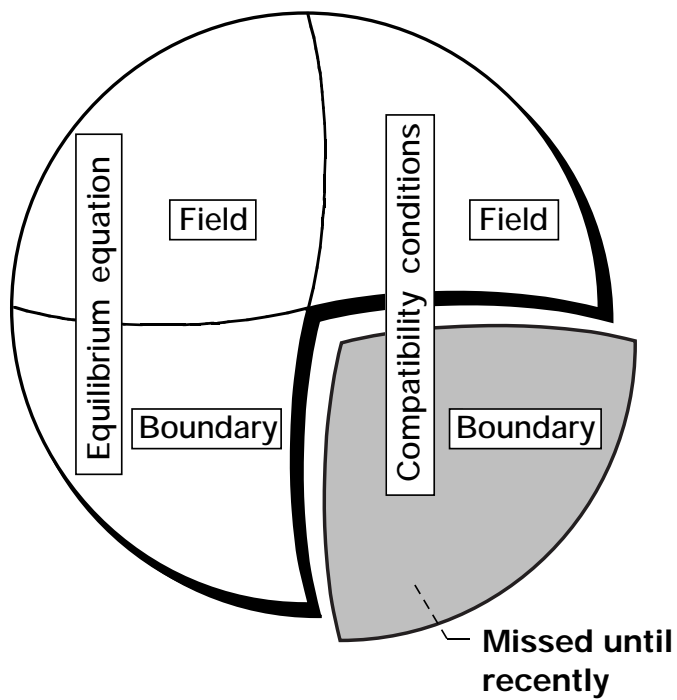

Figure 9.-Equilibrium equations and compatibility conditions in elasticity. 
Public reporting burden for this collection of information is estimated to average 1 hour per response, including the time for reviewing instructions, searching existing data sources, gathering and maintaining the data needed, and completing and reviewing the collection of information. Send comments regarding this burden estimate or any other aspect of this collection of information, including suggestions for reducing this burden, to Washington Headquarters Services, Directorate for Information Operations and Reports, 1215 Jefferson Davis Highway, Suite 1204, Arlington, VA 22202-4302, and to the Office of Management and Budget, Paperwork Reduction Project (0704-0188), Washington, DC 20503.

\begin{tabular}{|l|l|l}
\hline 1. AGENCY USE ONLY (Leave blank) & $\begin{array}{c}\text { 2. REPORT DATE } \\
\text { November } 1999\end{array}$ & $\begin{array}{r}\text { 3. REPORT TYPE AND DATES COVERED } \\
\text { Technical Memorandum }\end{array}$ \\
\hline
\end{tabular}

\section{TITLE AND SUBTITLE}

Compatibility Conditions of Structural Mechanics

\section{FUNDING NUMBERS}

WU-523-22-13-00

\section{AUTHOR(S)}

Surya N. Patnaik, Rula M. Coroneos, and Dale A. Hopkins

\section{PERFORMING ORGANIZATION NAME(S) AND ADDRESS(ES)}

National Aeronautics and Space Administration

John H. Glenn Research Center at Lewis Field

Cleveland, Ohio 44135-3191
8. PERFORMING ORGANIZATION REPORT NUMBER

E-11682

\section{SPONSORING/MONITORING AGENCY NAME(S) AND ADDRESS(ES)}

National Aeronautics and Space Administration

Washington, DC 20546-0001

10. SPONSORING/MONITORING AGENCY REPORT NUMBER

NASA TM-1999-209175

\section{SUPPLEMENTARY NOTES}

Surya N. Patnaik, Ohio Aerospace Institute, 22800 Cedar Point Road, Cleveland, Ohio 44142; Rula M. Coroneos and Dale A. Hopkins, NASA Glenn Research Center. Responsible person, Surya N. Patnaik, organization code 5930, (216) 433-5916.

This publication is available from the NASA Center for AeroSpace Information, (301) 621-0390.

\section{ABSTRACT (Maximum 200 words)}

The theory of elasticity has camouflaged a deficiency in the compatibility formulation since 1860 . In structures the ad hoc compatibility conditions through virtual "cuts" and closing "gaps" are not parallel to the strain formulation in elasticity. This deficiency in the compatibility conditions has prevented the development of a direct stress determination method in structures and in elasticity. We have addressed this deficiency and attempted to unify the theory of compatibility. This work has led to the development of the integrated force method for structures and the completed BeltramiMichell formulation for elasticity. The improved accuracy observed in the solution of numerical examples by the integrated force method can be attributed to the compliance of the compatibility conditions. Using the compatibility conditions allows mapping of variables and facile movement among different structural analysis formulations. This paper reviews and illustrates the requirement of compatibility in structures and in elasticity. It also describes the generation of the conditions and quantifies the benefits of their use. The traditional analysis methods and available solutions (which have been obtained bypassing the missed conditions) should be verified for compliance of the compatibility conditions.

\begin{tabular}{|c|c|c|}
\hline $\begin{array}{l}\text { 14. SUBJECT TERMS } \\
\text { Compatibility conditions } \\
\text { Elasticity }\end{array}$ & Finite element method; Integra & force method; Structures; \\
\hline $\begin{array}{l}\text { 17. SECURITY CLASSIFICATION } \\
\text { OF REPORT }\end{array}$ & $\begin{array}{l}\text { 18. SECURITY CLASSIFICATION } \\
\text { OF THIS PAGE }\end{array}$ & $\begin{array}{l}\text { 19. SECURITY CLASSIFICATION } \\
\text { OF ABSTRACT }\end{array}$ \\
\hline Unclassified & Unclassified & Unclassified \\
\hline
\end{tabular}

15. NUMBER OF PAGES

16. PRICE CODE

A03

\section{LIMITATION OF ABSTRACT}

Standard Form 298 (Rev. 2-89) 